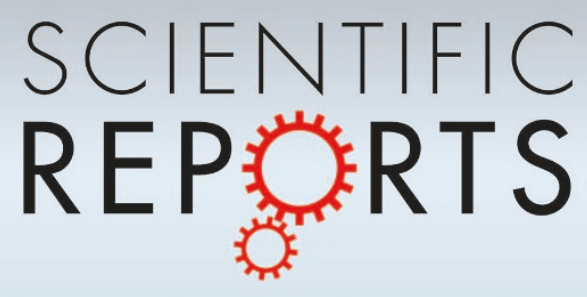

\section{OPEN}

SUBJECT AREAS:

ENVIRONMENTAL

CHEMISTRY

CHEMICAL ENGINEERING

Received

24 April 2014

Accepted

24 September 2014

Published

14 October 2014

Correspondence and requests for materials should be addressed to H.L. (hlee@kaist.ac.kr)

\footnotetext{
* These authors contributed equally to
} this work.

\title{
Nondestructive natural gas hydrate recovery driven by air and carbon dioxide
}

\author{
Hyery Kang ${ }^{1 *}$, Dong-Yeun Koh ${ }^{1 *} \&$ Huen Lee ${ }^{1,2}$
}

\begin{abstract}
'Department of Chemical and Biomolecular Engineering, Korea Advanced Institute of Science and Technology, 291 Daehak-ro, Guseong-dong, Yuseong-gu, Daejeon 305-701, South Korea, ${ }^{2}$ Graduate School of EEWS, Korea Advanced Institute of Science and Technology, 291 Daehak-ro, Guseong-dong, Yuseong-gu, Daejeon 305-701, South Korea.
\end{abstract}

Current technologies for production of natural gas hydrates (NGH), which include thermal stimulation, depressurization and inhibitor injection, have raised concerns over unintended consequences. The possibility of catastrophic slope failure and marine ecosystem damage remain serious challenges to safe NGH production. As a potential approach, this paper presents air-driven NGH recovery from permeable marine sediments induced by simultaneous mechanisms for methane liberation (NGH decomposition) and $\mathrm{CH}_{4}$-air or $\mathrm{CH}_{4}-\mathrm{CO}_{2} /$ air replacement. Air is diffused into and penetrates NGH and, on its surface, forms a boundary between the gas and solid phases. Then spontaneous melting proceeds until the chemical potentials become equal in both phases as NGH depletion continues and self-regulated $\mathrm{CH}_{4}$-air replacement occurs over an arbitrary point. We observed the existence of critical methane concentration forming the boundary between decomposition and replacement mechanisms in the NGH reservoirs. Furthermore, when $\mathrm{CO}_{2}$ was added, we observed a very strong, stable, self-regulating process of exchange $\left(\mathrm{CH}_{4}\right.$ replaced by $\mathrm{CO}_{2} /$ air; hereafter $\mathrm{CH}_{4}-\mathrm{CO}_{2}$ /air) occurring in the NGH. The proposed process will work well for most global gas hydrate reservoirs, regardless of the injection conditions or geothermal gradient.

$\mathrm{N}$ atural gas hydrates (NGHs) are solid, non-stoichiometric compounds containing a large amount of natural gas in deep sea sediments or permafrost regions and they have strong potential as a nextgeneration energy source ${ }^{1,2}$. How to efficiently and safely exploit the tremendous amount of natural gas stored as gas hydrate underneath the surface of the earth remains an urgent challenge, and fortunately several field trials for NGH production have suggested a hopeful new prospect for using gas hydrates as energy resources. Recently, one onshore field trial was carried out in 2012 on the Alaska North Slope in the United States of America $^{3}$, and the first offshore field trial was attempted in 2013 in the Eastern Nankai Trough in Japan ${ }^{4,5}$. Meanwhile, in Korea, two Ulleung Basin Gas Hydrate (UBGH) Drilling Expeditions were carried out (2007 and 2010), and they confirmed the existence of considerable amounts of NGH in the deep-sea sediments there ${ }^{6-8}$. A UBGH field production test is scheduled for mid-2015 at the sites (UBGH 2-6) with geological conditions providing the greatest potential ${ }^{8}$.

The currently proposed technologies for marine NGH production are generally derived from standard methods used in conventional oil and gas industries. These take advantage of the driving potential of differences in temperature, pressure and chemical potential, which cause significant changes in the conditions within NGH reservoirs. Thermal stimulation causes vacillation between NGH formation and dissociation temperatures $(\Delta T)$, depressurization shifts the reservoir pressure to much lower than NGH-formation pressure $(\Delta \mathrm{P})$, and inhibitor injection alters the chemical environment $(\Delta \mu)$ of the NGH to inhibit the stable formation of gas hydrates? However, these methods are all dissociation-based technologies, which can raise serious concerns about repercussions such as slope failure and seabed ecosystem destruction ${ }^{10}$. $\mathrm{A} \mathrm{CH}_{4}$-replacement mechanism driven by $\mathrm{CO}_{2}$ injection has recently been suggested as a plausible new approach to production ${ }^{11,12}$. It has the potential of being a nondestructive means by which energy production and carbon dioxide sequestration might be achieved simultaneously. However, under the harsh conditions of naturally occurring gas hydrate sites, injected $\mathrm{CO}_{2}$ gas readily transforms to a liquid state, slowing and weakening its soaking and migration. Undesirable fluctuation between the two $\mathrm{CO}_{2}$ phases (gas and liquid) makes injection and diffusion very unstable, which can possibly lead to a low replacement rate and recovery yield. To overcome such weaknesses, in previous reports, we proposed the use of a gaseous mixture of $\mathrm{N}_{2}$ and $\mathrm{CO}_{2}{ }^{13-15}$. The overall recovery of methane was greatly improved by specific attack of 
$\mathrm{CH}_{4}$ molecules in the small cages of structure (sI) with added $\mathrm{N}_{2}$ molecules. In a field production test on the Alaska North Slope in 2012 , the $\mathrm{CO}_{2} / \mathrm{N}_{2}$ injection method was adopted as the main process and was successfully performed ${ }^{3}$.

At this stage, we note that each NGH reservoir around the globe has its own distinctive geological characteristics, and that these need to be fully examined to determine compatible production techniques. These NGH geological characteristics also vary with formation depth and are determined by reservoir pressure and temperature. For example, the temperature and pressure ranges around $278 \mathrm{~K}$ and 70 bar on the Alaska North Slope. The NGH site in the Nankai Trough of Japan is located at a depth near $1000 \mathrm{~m}$ and $\sim 287 \mathrm{~K}$. In the UBGH site, the ranges of temperature and pressure are 288$293 \mathrm{~K}$ and 200-220 bar, respectively. The pressure exerted on an NGH site is determined by the hydraulic pressure exerted by the water column (depth), but the surrounding temperature may be much higher than expected because of a geothermal gradient of the $\mathrm{NGH}$ bearing sediment. The two exchange approaches using $\mathrm{CH}_{4}$ $\mathrm{CO}_{2}$ and $\mathrm{CH}_{4}-\mathrm{CO}_{2} / \mathrm{N}_{2}$ are to a certain degree adaptable, but in reality, we still need to develop a more feasible approach to deal with huge amounts of NGH at various conditions.

In this work, we demonstrate an NGH production method using air and $\mathrm{CO}_{2}$ /air. Air is abundant and is available at any time and at any location, which makes it the most attractive element for practical production of $\mathrm{NGH}$. It is known that $\mathrm{N}_{2}$ and $\mathrm{O}_{2}$ gases can play a role in breaking down methane hydrates because of the chemical potential difference $(\Delta \mu)$ between their gas and solid phases ${ }^{16-18}$. Earlier such methods for replacement and dissociation were only considered for use in systems with very dilute methane hydrates ${ }^{13-18}$. Accordingly, a continuous supply of fresh air into the NGH can make it melt completely. However, the methane concentration in the recovered gas becomes quite small, requiring additional separation facilities. The use of pure air contributes to methane production by NGH melting, but the key issue arises as to whether replacement can occur when we further extend the systems with concentrated methane hydrates or injection of $\mathrm{CO}_{2}$-enriched air $\left(\mathrm{CO}_{2} /\right.$ air $)$. To address in detail the process of releasing methane from $\mathrm{NGH}$ using air or $\mathrm{CO}_{2}$ /air, we defined the new variable 'critical methane concentration' (CMC), which consists of the number of methane and injected molecules, and performed experiments to reveal the mechanisms involved (Fig. 1a).

\section{Results}

The initial stage of air injection is intended to strongly decompose the $\mathrm{NGH}$, release the methane and finally alter the gas-phase composition around the NGH. Meanwhile, the guest species of nitrogen and oxygen are expected to possess strong potential for forming pure, as well as mixed, hydrates. At this point, the following issue arises and needs to be addressed. How does air drive the NGH to melt? The fresh air might have the maximum potential for decomposing $\mathrm{NGH}$, but gradually weakens and eventually loses its methane recovery capacity at a certain methane concentration. The NGH is continuously depleted until the chemical potentials of methane in both the solid NGH and gas phases are equal, and right after an arbitrary point, decomposition of methane hydrate stops and anomalous preservation of the hydrate phase occurs.

Now, we define the ratio between the methane concentration in hydrate $\left(\mathrm{nCH}_{4}\right)$ and the injected gaseous air (or $\mathrm{CO}_{2}$ /air; nair or $\mathrm{nCO}_{2}$ /air) at equal chemical potentials as the 'critical methane concentration' (CMC). The CMC plays a central role in determining methane recovery from NGH and can be influenced by complex surrounding factors such as the depth of marine $\mathrm{NGH}$, geothermal gradient, sediment geochemistry and amount of saturated pore water.

For precise $\mathrm{CMC}$ analysis we, above all, limited the experimental scope to the achievement of either complete or partial NGH decomposition. We used a fixed-volume high-pressure reactor, controlling the molar ratio between methane in the $\mathrm{NGH}$ and air $\left(\mathrm{nCH}_{4} /\right.$ nair $)$ according to the initial NGH amount. The temperature was fixed at $288.15 \mathrm{~K}$ and air was injected at 200 bar to match closely the conditions found in the UBGH in the East Sea of Korea. When a large amount of air $\left(\mathrm{nCH}_{4} \ll\right.$ nair) was present, complete NGH decomposition occurred (Fig. 1b, left part of dotted line), thus leading to $\mathrm{NGH}$ depletion. In other words, the continuous supply of fresh air to $\mathrm{NGH}$ will make it possible for the gaseous phase to be in a more $\mathrm{CH}_{4}$ dilute state, maintaining its value lower than the CMC, and thereby favorably leading to full decomposition of methane hydrates. Here, it becomes quite interesting to see what occurred above the CMC. We observed the partial NGH decomposition (Fig. 1b, right part of dotted line). Thus, we identify three phenomenological stages: release of methane molecules from $\mathrm{NGH}, \mathrm{NGH}$ structure destruction via melting and increase in the concentration of gaseous methane, which are all caused by the chemical potentials of guest-molecules. Approaching the dynamic equilibrium between solid NGH and gaseous air-methane, the vigorous escape of methane from NGH is suppressed and eventually ceases. Accordingly, it is interesting to determine the lowest methane concentration (CMC) that limits methane production from NGH. The complete NGH decomposition at the CMC can readily be confirmed visually, but above the CMC, a noticeable amount of NGH still remains (Fig. 1c).

When the ratio of $\mathrm{CH}_{4}$-air is greater than $\mathrm{CMC}$, some methane hydrates dissociate and water is produced. Simultaneously, the formation of gas hydrate is initiated by the gas mixture of injected gas and released $\mathrm{CH}_{4}$. Finally, there is methane contained in the hydrate phase but it is inseparable between initially existent $\mathrm{CH}_{4}$ and reformed $\mathrm{CH}_{4}$ in hydrate. To obtain more detailed structural and compositional information above the $\mathrm{CMC}$, NGH samples remaining after sufficient exposure to air $\left(\mathrm{nCH}_{4} \gg\right.$ nair) have to be carefully quenched (see Methods) and analyzed for clear identification of solid phases that might form with the aid of air. The Raman spectra (Fig. 2a) of two samples formed from different methane-air mole ratios ( $>$ CMC) reveal that the injected $\mathrm{N}_{2}$ and $\mathrm{O}_{2}$ molecules are continuously encaged in NGH until the equilibrium state is reached ${ }^{19,20}$. Stable capture of air components in sI-S and sI-L strongly implies that NGH decomposition, after gas injection, causes chemical replacement even at high temperatures, in the UBGH condition. In addition, the corresponding PXRD patterns (Fig. 2b) confirm that a mixed hydrate structure remains in the Cubic Structure I (sI) phase. These two spectroscopic results suggest that guestreplacement is likely to occur beyond the CMC. The water coming from partial dissociation of the hydrate by air injection is represented as hexagonal ice $\left(\mathrm{I}_{h}\right)$ because the PXRD patterns were analyzed at $93 \mathrm{~K}$. Quantitative analysis was conducted to find the relative contributions of the two key mechanisms, decomposition and replacement. The main peak intensities were determined by profile-matching the whole-pattern within the space group corresponding to structures ice $\mathrm{I}_{\mathrm{h}}$ and $\mathrm{sI}$.

Now we will focus on extending the phenomenological concept of air-based NGH decomposition to the $\mathrm{CH}_{4}-\mathrm{CO}_{2}$ /air approach. Carbon dioxide is known to be a strong hydrate former and thus carbon dioxide mixed with air $\left(20 \mathrm{~mol} \%\right.$ of $\left.\mathrm{CO}_{2}\right)$ slows the $\mathrm{NGH}$ decomposition rate. We note that the $\mathrm{CMC}$ is dramatically lowered to 0.418 when $\mathrm{CO}_{2}$ is added as a second guest (solid diamond in Fig. 1b). Fig. 3 shows the incorporations of $\mathrm{N}_{2}, \mathrm{O}_{2}$ and $\mathrm{CO}_{2}$ into the gas hydrate structure when the ratio of $\mathrm{CH}_{4}-\mathrm{CO}_{2}$ /air exceeds $\mathrm{CMC}$. Furthermore, we conducted the same experiment using real UBGH samples from the core section of UBGH-2-6-C. SEM images of the sediments are presented in Fig. 4 . When the $\mathrm{CH}_{4}$-to- $\mathrm{CO}_{2} /$ air ratios are greater than 0.418 , which is the $\mathrm{CMC}$ for $\mathrm{CO}_{2} /$ air $(20 \mathrm{~mol} \%$ of $\mathrm{CO}_{2}$ ), incorporation of gases in the gas hydrate structure is observed in the both pure gas hydrate system (Fig. 3a-d) and the UBGH system (Fig. 3e-h). Each of eight figures is presented in Supplementary Fig. S1-8. 

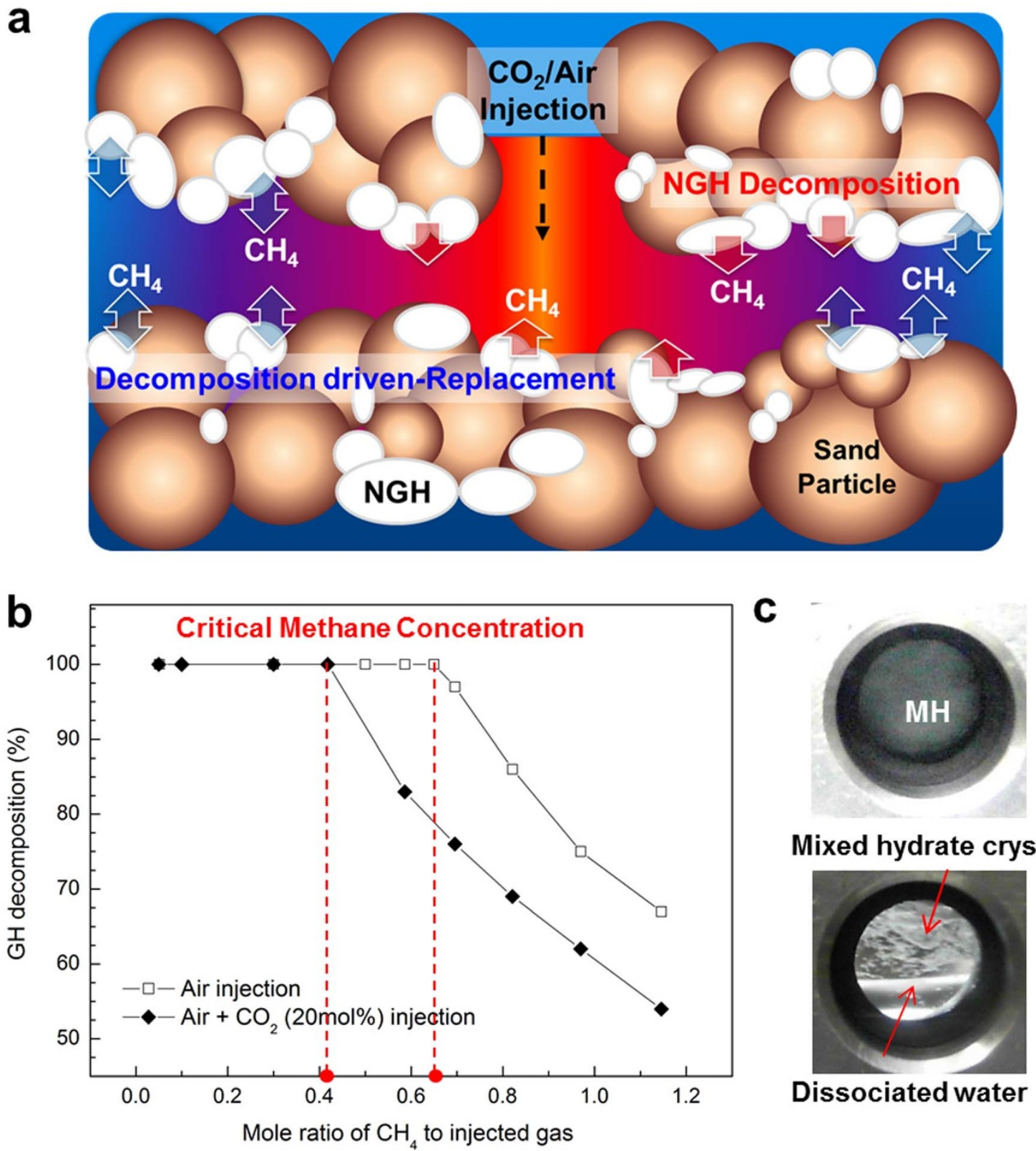

\section{Mixed hydrate crystals}

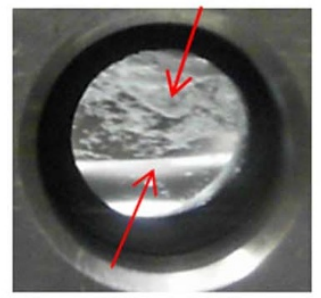

Dissociated water

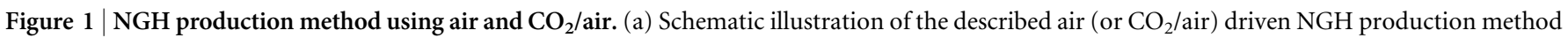
composed of two distinct steps: NGH decomposition caused by injected air (or $\mathrm{CO}_{2} /$ air); subsequent decomposition driven guest exchange process.

(b) Discovery of the concept of critical methane concentration (CMC) depending on the molar ratio between $\mathrm{CH}_{4}$ and injected air and $\mathrm{CO}_{2} /$ air.

(c) Methane hydrate at $288.15 \mathrm{~K}$ and 200 bar before air injection (top), and mixed hydrate crystals coexist with water at $288.15 \mathrm{~K}$ after air injection above the critical concentration (bottom).

Another important aspect of this research was to explore the effect of temperature and pressure on CMC-related behavior. We demonstrated the potential applicability of air and $\mathrm{CO}_{2}$ /air injection to three $\mathrm{NGH}$ production test sites on the Alaska North Slope (USA), Nankai Trough (Japan) and Ulleung Basin (Korea), and the results are shown in Fig. 5. Representative pressures and temperatures from those sites were specified for the upcoming CMC analysis. To see the degree of NGH decomposition, we first injected pure air into the NGH and found a relatively high CMC of $0.53-0.65$. The CMC gradually decreased as the $\mathrm{NGH}$ pressure and temperature decreased. It is again worth noting that the injection of pure air and $\mathrm{CO}_{2}$ /air can simultaneously drive the two distinct mechanisms (decomposition and replacement) needed for NGH recovery. Through such a concept (combined hybrid production), we need to establish the process boundaries of the predominant mechanisms occurring in real NGH fields. When $5 \mathrm{~mol} \%$ of carbon dioxide is added to pure air, its CMC shows a reduction of $10-18 \%$ compared with pure air alone, depending on surrounding conditions at the NGH sites. Several more tests revealed that the CMC generally decreases with increasing $\mathrm{CO}_{2}$. The lowering of the $\mathrm{CMC}$ by the activity of carbon dioxide results in a noticeable reduction of the NGH decomposition rate, and is probably linked closely to its potential for guestexchange with methane. We thus conclude that use of high- $\mathrm{CO}_{2}$ in air leads to replacement-dominant $\mathrm{NGH}$ recovery.

Here, we notice that both $\mathrm{CO}_{2}$ and $\mathrm{CH}_{4}$ form sI hydrates, while air composed of $\mathrm{N}_{2}$ and $\mathrm{O}_{2}$ forms sII structures. Thus, we need to carefully analyze the structural patterns resulting from the complex interactions of the injected guest species of $\mathrm{CO}_{2}, \mathrm{~N}_{2}$ and $\mathrm{O}_{2}$. According to the PXRD pattern (see Supplementary Fig. S9a), the sII hydrates prevail in $1 \mathrm{~mol} \% \mathrm{CO}_{2}$ in air gas, but in $3-20 \mathrm{~mol} \%$ $\mathrm{CO}_{2}$, sI hydrate formation becomes possible. For verification of 


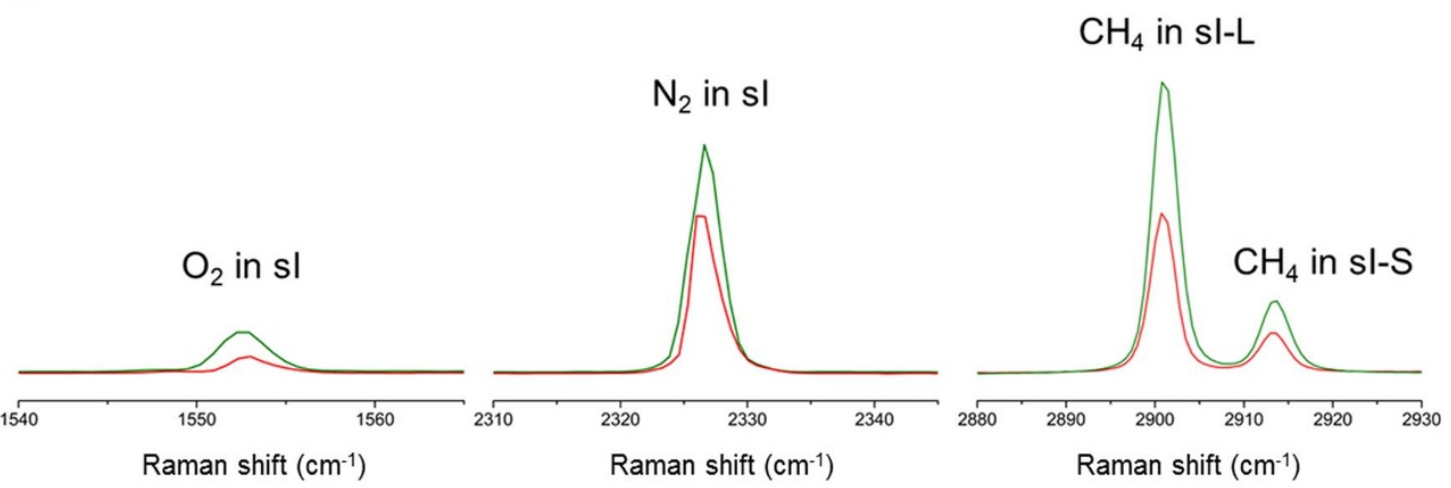

b

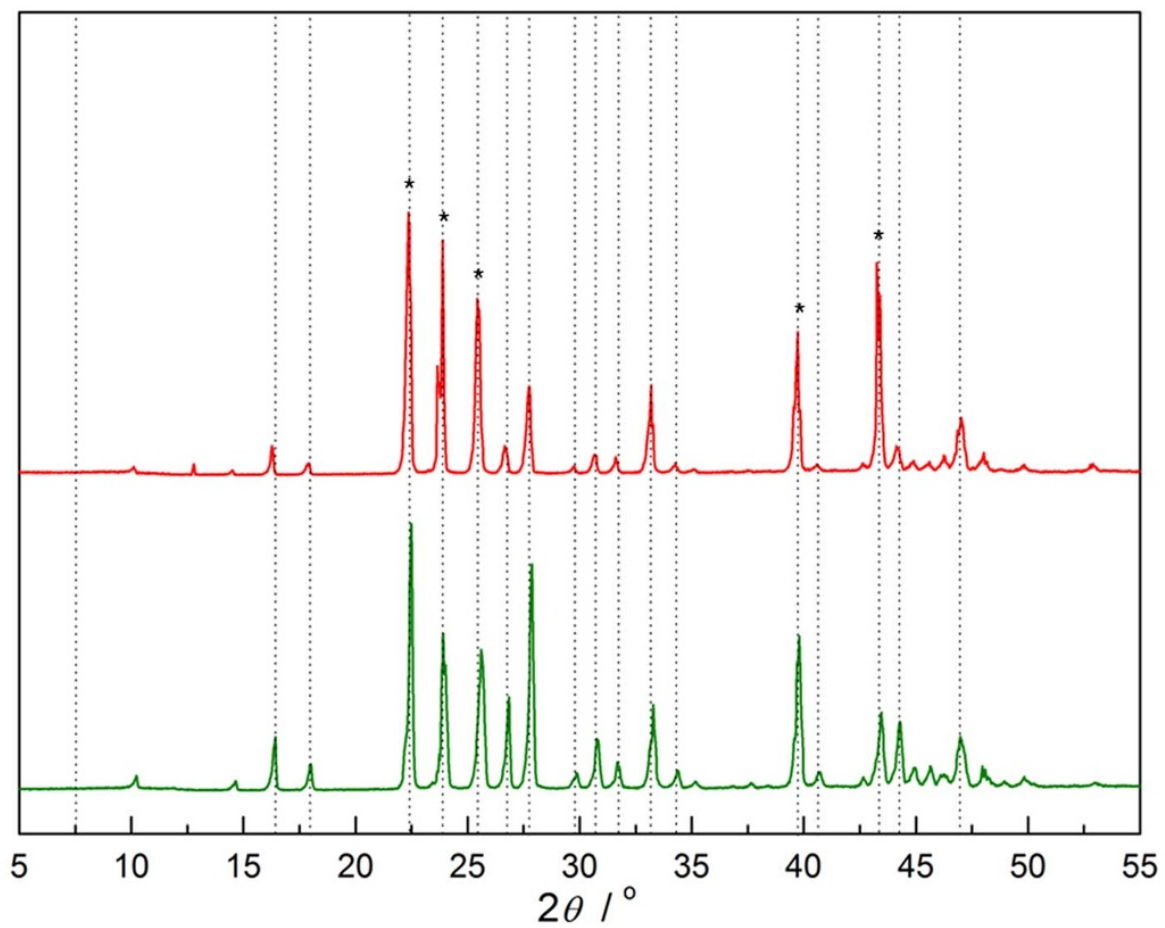

Figure $2 \mid$ Formation of mixed sI hydrate beyond the critical molar ratio. Red line represents the hydrate phase when methane-air mole ratio is 2.01. Green line corresponds to the hydrate phase when the ratio is 5.65. (a) The Raman spectra of the mixed $\mathrm{N}_{2}+\mathrm{O}_{2}+\mathrm{CH}_{4}$ hydrate at $77 \mathrm{~K}$. (b) PXRD patterns of each hydrate at $93 \mathrm{~K}$. Asterisks in (b) indicate reflections from hexagonal ice $\left(\mathrm{I}_{\mathrm{h}}\right)$ phase.

stability we measured three phase $(\mathrm{H}+\mathrm{L}+\mathrm{V})$ equilibria using the isochoric process (see Supplementary Fig. S9b) ${ }^{21}$. Additionally, we observed that just a small increase in the carbon dioxide concentration in the vapor phase causes a significant increase of it in the mixed $\mathrm{CO}_{2}$ /air hydrate phase (see Supplementary Table S1).

To see patterns for mixed hydrates that have larger $\mathrm{CH}_{4}-\mathrm{CO}_{2}$ /air mole ratios than at CMC, we carried out ex-situ HRPD experiments using the 9B beam line of the Pohang Accelerator Laboratory (see Supplementary Fig. S10). First, we determined the CMC of 0.418 in the ratio of $\mathrm{CO}_{2} /$ air $(2: 8)$ and then observed the chemical exchange that occurred above the CMC. For comparison, the HRPD pattern at a $\mathrm{CH}_{4}$-air mole ratio of 2.53 is represented by the black line. From structural analysis we confirmed the coexistence of Structure I gas hydrate and hexagonal ice when either air or $\mathrm{CO}_{2}$ /air was injected into the NGH and we obtained their relative amounts by entirepattern fitting. The compositions of the sI gas hydrates were analyzed using GC. Thus the combined refined HRPD (ice to sI ratio) and GC results (replacement efficiency revealed by remaining gas composition in the hydrate phase) are shown as relative contributions of decomposition and replacement (Fig. 6). The detailed descriptions for the quantitative analysis can be found in Methods. $\mathrm{CH}_{4}$ recovery by decomposition is shown as gray bars and $\mathrm{CH}_{4}$ recovery by replacement is shown as shaded bars. The sum of these two bars is the rate of total $\mathrm{CH}_{4}$ recovery. Solid lines represent the ratio between ' $\mathrm{CH}_{4}$ recovery by decomposition' and ' $\mathrm{CH}_{4}$ recovery by replacement' in each sample. Interestingly, directly above the CMC, considerable amounts of $\mathrm{CO}_{2}, \mathrm{~N}_{2}$, and $\mathrm{O}_{2}$ initiated replacement of $\mathrm{CH}_{4}$ in the $\mathrm{NGH}$, even under harsh, deep-sea conditions. Particularly, we note that the contribution of replacement to NGH recovery (versus the contribution of decomposition) became more significant as the ratio of methane to $\mathrm{CO}_{2}$ /air increased. Another notable feature is that the NGH production concept based on the CMC can be unrestrainedly applicable to a variety of geological settings with site-specific hydraulic pressures and geothermal gradients (red line in Fig. 6 shows UBGH sediment effect).

\section{Discussion}

The formation of pure $\mathrm{N}_{2}$ or/and $\mathrm{O}_{2}$ hydrate requires harsh $\mathrm{p}$-T conditions compared to the mild formation condition for pure $\mathrm{CH}_{4}$ hydrate. However, when the $\mathrm{CH}_{4}$ hydrates are pre-existing 


\section{GH (Pure methane hydrate)}
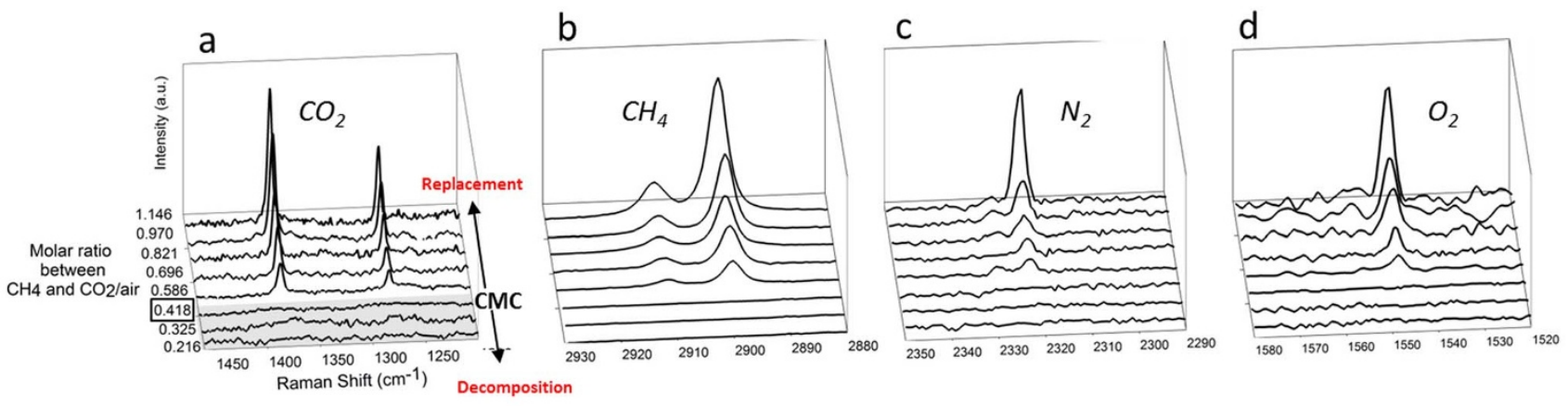

UBGH (NGH, East Sea)
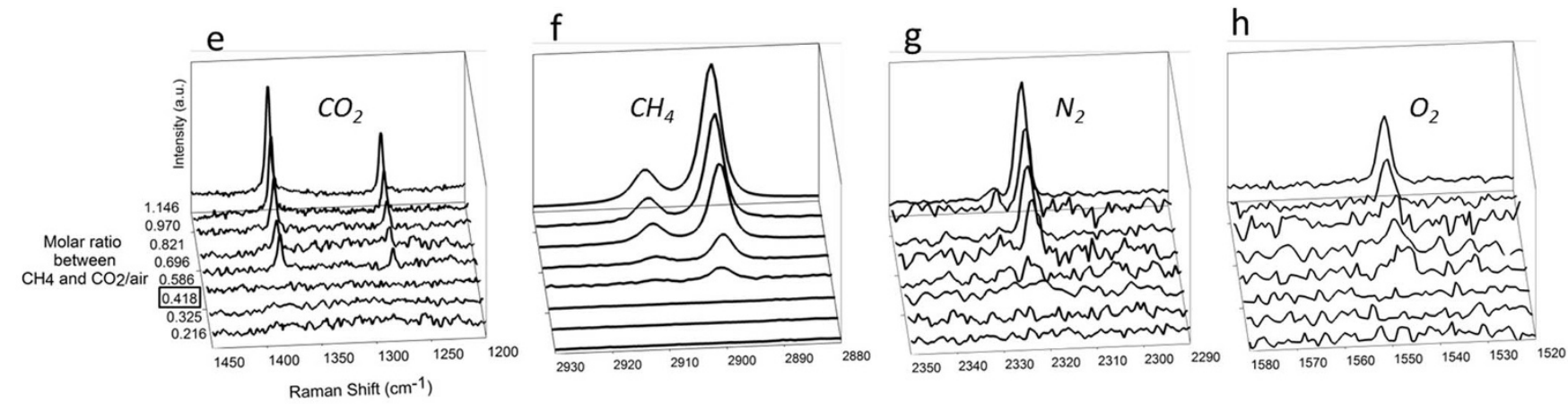

Figure 3 Direct visualization of guest-exchange analyzed by the Raman spectra after the injection of $\mathrm{CO}_{2} /$ air $\left(20 \mathrm{~mol} \% \mathrm{CO}_{2}\right.$ and $80 \mathrm{~mol} \%$ air $)$ into pure $\mathrm{CH}_{4}$ hydrate (a-d) and NGH (e-h). $\mathrm{CO}_{2}$ /air injection was performed at $288.15 \mathrm{~K}$ and 200 bar. As the $\mathrm{CH}_{4}-\mathrm{CO}_{2} /$ air ratio increased, significant encapsulation of $\mathrm{CO}_{2}, \mathrm{~N}_{2}$, and $\mathrm{O}_{2}$ molecules in the hydrate cages were detected. (a, e) C-O stretching and bending vibrational modes of $\mathrm{CO}_{2}$ molecules in the large cages of the hydrate; (b, f) C-H stretching vibrational modes of $\mathrm{CH}_{4}$ molecules in the hydrate; (c, g) N-N stretching vibrational modes of $\mathrm{N}_{2}$ molecules in the hydrate; $(\mathrm{d}, \mathrm{h}) \mathrm{O}-\mathrm{O}$ stretching vibrational modes of $\mathrm{O}_{2}$ molecules in the hydrate.
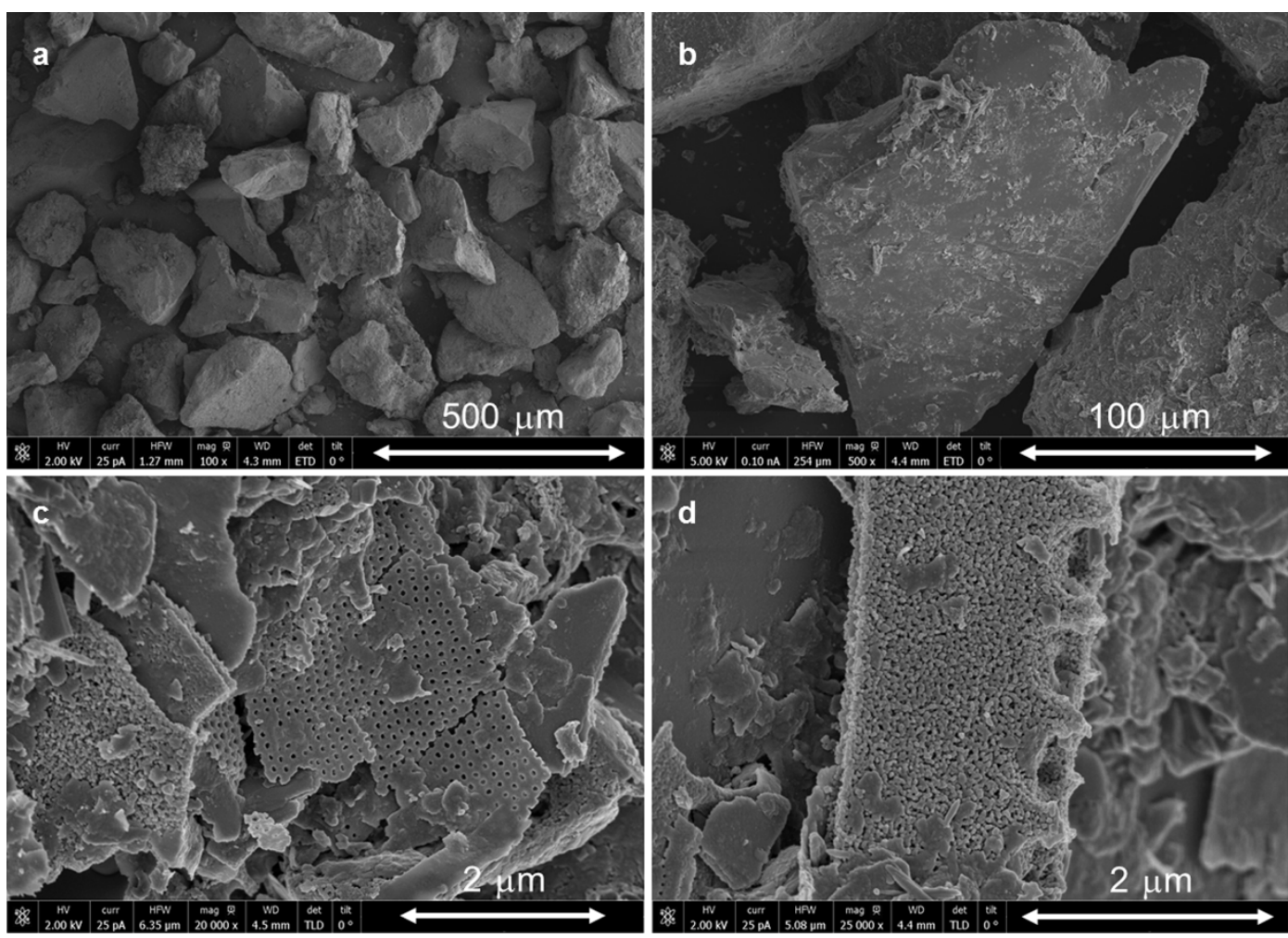

Figure 4 | SEM images on dry sediments selected from the core section UBGH2-6-C. 


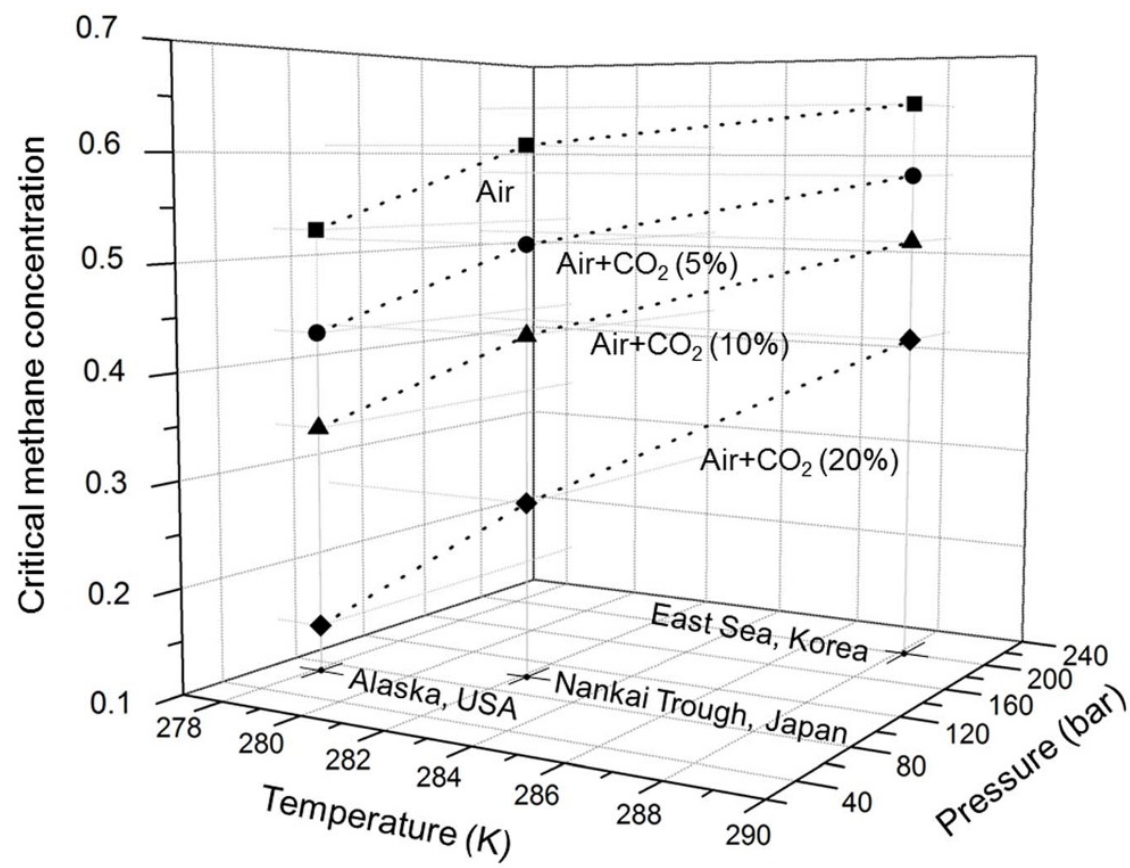

Figure $5 \mid$ CMC observed in the three representative $\mathrm{NGH}$ reservoirs with different $\mathrm{CO}_{2}$ concentrations. Solid squares indicate pure air injection. Solid circles, triangles and diamonds indicate 5, 10 and $20 \mathrm{~mol} \% \mathrm{CO}_{2}$ in air gas, respectively. The dotted lines are the guides to the eyes.

and gases are injected into the pre-existing $\mathrm{CH}_{4}$ hydrates, as the NGH reservoirs, the circumstance is different from that of pure gas hydrate formation condition. When pre-existing $\mathrm{CH}_{4}$ hydrates come into contact with the foreign gases such as air or $\mathrm{CO}_{2}$ /air, slight decomposition of the $\mathrm{CH}_{4}$ hydrate is inevitable. Moreover, $\mathrm{CH}_{4}$ released from the pre-existing gas hydrates changes the composition of the gas phase $\left(\mathrm{CH}_{4}+\mathrm{N}_{2}+\mathrm{O}_{2}\right.$ or $\mathrm{CH}_{4}+\mathrm{N}_{2}+\mathrm{O}_{2}+\mathrm{CO}_{2}$ gas mixture), and eventually the change in gas composition causes the injected air or $\mathrm{CO}_{2}$ /air gas to form the hydrates after all. This is why we introduced the concept of the 'Critical Methane Concentration'.
When the ratio of $\mathrm{CH}_{4}$ to air or $\mathrm{CO}_{2}$ /air is less than or equal to the $\mathrm{CMC}$, all $\mathrm{CH}_{4}$ hydrates dissociate. However, when the ratio is higher than CMC, partial decomposition of methane hydrate is observed and injected air or $\mathrm{CO}_{2}$ /air form many gas hydrates. That is to say, we note that the phase equilibrium data of the injected gas is not the only criterion for determining whether or not the replacement can occur.

The most urgent task to advance NGH production is to find an economically feasible means that can proceed by spontaneous, natural processes. As a major future energy resource, NGH may compete with shale gas only if we can reduce the cost of primary

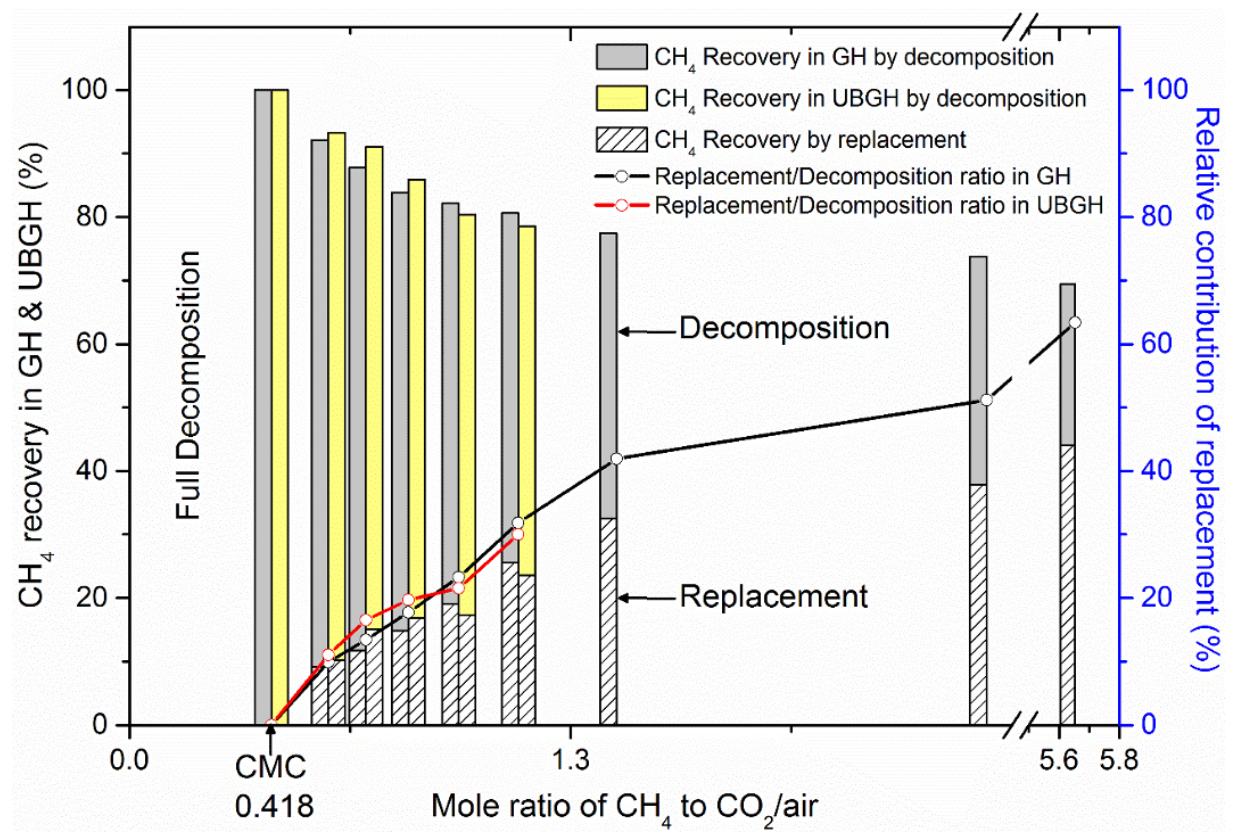

Figure 6 Decomposition/replacement ratio beyond the CMC observed under the conditions in the East Sea using $\mathrm{CO}_{2} /$ air $\left(20 \mathrm{~mol} \% \mathrm{CO}_{2}\right.$ and $80 \mathrm{~mol} \%$ air) gas. Black and yellow bars represent total $\mathrm{CH}_{4}$ recovery rates based on combination of decomposition and replacement in the pure $\mathrm{GH}$ and $\mathrm{UBGH}$, respectively. When $\mathrm{CH}_{4}$ to $\mathrm{CO}_{2} /$ air ratio exceeds the $\mathrm{CMC}$, replacement between $\mathrm{CH}_{4}$ and $\mathrm{CO}_{2} /$ air initiates. Shaded areas represent the fraction of replacement in the total $\mathrm{CH}_{4}$ recovery and solid lines represent relative contributions of replacement in each case. 
production from large NGH deposits. Depressurization has been attempted in NGH field tests, most recently in the Nankai Trough (Japan). We understand that, by whatever method we choose, methane gas will be released from solid NGH by melting, by decomposition or by replacement via chemical exchange. A number of strongly influential variables that drive methane extraction control the two different NGH production mechanisms, while which of the two mechanisms is predominant remains to be determined.

From the insights gained from this study, we suggest a plausible strategy for extracting fuels from $\mathrm{NGH}$. In the first phase, $\mathrm{CO}_{2}$ (transported from inland sources) and compressed air is mixed insitu to prepare for injection into the NGH layer. This 'in-situ mixing' concept allows a very effective preparation procedure for injecting gas mixtures. Liquid $\mathrm{CO}_{2}$ transported from the inland sources is then mixed with compressed air captured above the production test field to produce the $\mathrm{CO}_{2}$ /air gas mixture. The $\mathrm{CO}_{2}$ /air gas mixture is then injected into the sediment and diffused throughout the NGH layers. The first contact between the $\mathrm{CO}_{2}$ /air gas mixture and the gas hydrates will induce decomposition of a certain portion of $\mathrm{NGH}$ in the sediments. This decomposition step eventually increases the partial pressure of $\mathrm{CH}_{4}$ inside the NGH layer and induces a 'decomposition driven-replacement process'. The increased population of $\mathrm{CH}_{4}$ molecules significantly reduces the thermodynamic barrier for replacement reactions. This replacement process enhances the geomechanical stability of the NGH layer by forming stable hydrate lattices. Here, we again note that the nondestructive replacement process preserves host water-lattices in the NGH-bearing sediments as part of the newly formed air or $\mathrm{CO}_{2}$ /air hydrates. In contrast, $\mathrm{NGH}$ decomposition by depressurization requires large volumes of water to be displaced from the NGH. Furthermore, the ensuing endothermic temperature drop caused by decomposition can result in undesirable formation of secondary methane hydrate or ice in the well and near the wellbore. The chemical exchange of dissimilar guest molecules does not involve significant cooling ${ }^{22}$, and thus the geomechanical stability of gas hydrate-bearing sediments is less threatened.

We present three key aspects of our findings: 1) We defined a new factor (CMC) related to the methane recovery rate from natural gas hydrates, 2) We obtained CMC values for three distinct conditions (simulating three representative reservoirs) experimentally, and 3) We verified that starting decomposition leads to replacement of methane by injected air or $\mathrm{CO}_{2}$ /air in NGH. According to the present outcomes, we conclude that the proposed process is likely the efficient, nondestructive and commercially-viable means (compared to conventional ones) for onshore and offshore methane production from $\mathrm{NGH}$, and it can be widely adapted to diverse geological conditions. We acknowledge that the $\mathrm{CH}_{4}$ cage occupancies of naturally occurring gas hydrates may differ depending on the surrounding conditions, such as the sediment type, the methane saturation percentage in the pore water, and the macroscopic morphology of the gas hydrate, among others. Therefore, to apply CMC fully in the field of gas hydrate production, general trends pertaining to the cage occupancy of target production sites are required.

\section{Methods}

Materials. Water of ultrahigh purity was obtained from a Millipore purification unit. $\mathrm{CH}_{4}$, air $\left(\mathrm{O}_{2} 21 \mathrm{~mol} \%\right.$ and $\mathrm{N}_{2}$ balance $)$ and $\mathrm{CO}_{2} /$ air gas were purchased from the Special Gas Company (Daejeon, Republic of Korea), with a stated minimum purity of $99.95 \mathrm{~mol} \%$.

Sample preparation and gas injection procedures. To assess the effect of the molar ratio of $\mathrm{CH}_{4}$ and air (or $\mathrm{CO}_{2}$ /air), we used a fixed-volume high-pressure stirred reactor. First, we charged the reactor with the desired volume of water and charged 200 bar of methane gas at $288.15 \mathrm{~K}$. The formation of methane hydrate was achieved by decreasing the temperature in an isochoric condition. The heating-cooling cycle was repeated to confirm the complete conversion of water to methane hydrate. When the methane hydrate was fully formed, additional methane gas was supplied to recover pressure reduction due to hydrate formation. When the pressure and temperature were stabilized at the desired conditions (e.g., 200 bar and $288.15 \mathrm{~K}$ ), methane gas in the reactor was rapidly exchanged with air (or $\mathrm{CO}_{2} /$ air) using a syringe pump (ISCO, model 260D). To prevent the dissociation of methane hydrates during the gas exchange, we used a back-pressure regulator to maintain a constant pressure (e.g., 200 bar). Also, in order to eliminate the heating effect of air, air pre-cooled to a temperature of $288.15 \mathrm{~K}$ was used. When we performed the gas exchange of methane with air or $\mathrm{CO}_{2}$ /air, we used another high-pressure reservoir cell in the same temperature-controlled bath (see Supplementary Fig. S11). The inner volume of the gas reservoir cell is $500 \mathrm{ml}$, and it served as a container for pre-cooled gas. During every exchange process, the container and an ISCO pump were pressurized 25\% higher (20-50 bar) than each target pressure before the injection process. For example, we pressurized the precooled reactor and ISCO pump at 250 bar when the target pressure was 200 bar. The back pressure regulator was set at an exact target pressure. Before performing the gas exchange experiments, we pre-tested the gas exchange capacity of our experimental setup with the empty cell $(50 \mathrm{ml})$ and confirmed the complete gas exchange ( $>99 \%$ ) via GC. It takes 30 seconds completely to replace the $\mathrm{CH}_{4}$ in the reactor with air (or $\mathrm{CO}_{2} /$ air). Once the volume of methane hydrate was obtained using the density of methane hydrate $\left(930 \mathrm{~kg} \mathrm{~m}^{-3}\right)^{23}$, the volume occupied by the injected gas became known, and the mole of the injected gas was calculated by applying an ideal gas law. In this way, the mole ratio between $\mathrm{CH}_{4}$ and air (or $\mathrm{CO}_{2}$ /air) was determined. In case of the UBGH sample, the physical properties of porosity and grain density for sand were acquired from KIGAM (the UBGH drilling expedition team), which was $70 \%$ and $2650 \mathrm{~kg} \mathrm{~m}^{-3}$. The pressure and temperature during the entire process was monitored using a custom-built Labview program, and we periodically checked if the pressure and temperature had reached constant values. We initially assessed the decomposition of hydrate using a lookthrough quartz window on the high-pressure reactor. When the ratio of $\mathrm{CH}_{4}$ to air (or $\mathrm{CO}_{2}$ /air) was smaller than the CMC, we confirmed the disappearance of the last hydrate crystal, as visual observation is widely used in determining the hydrate equilibrium conditions.

Mixed-phase gas hydrate sampling using liquid nitrogen quenched helium gas. When the reaction of the gas hydrate and air (or $\mathrm{CO}_{2} /$ air) was completed (confirmed by PT monitoring; finished within 72 hours), we took representative samples of the product for further spectroscopic analyses. To keep the original phase intact, we used rapid cooling method using liquid-nitrogen quenched helium gas and liquid nitrogen. If the gas in the reactor is vented to atmospheric pressure under ambient conditions, the original composition of the product would significantly change. Therefore, we rapidly exchanged the gas phase in the reactor with pre-cooled helium gases. Because helium retains its gaseous phase at the liquid-nitrogen temperature $(\sim 77 \mathrm{~K})$, the gas phase in the reactor was effectively exchanged to helium gas at the near-liquid nitrogen temperature. At the same time, the reactor was immersed in liquid nitrogen to freeze the whole reaction product rapidly. In this way, we kept the original phase composition of the product during the sampling procedure. When the product was completely frozen, it was ground into particles of less than 200 microns, and they were analyzed using spectroscopic tools (XRD/HRPD, Raman) and gas chromatography.

A quantitative analysis for decomposition/replacement beyond the critical methane concentration was performed by a combination of XRD/HRPD and GC results. When mole ratio of $\mathrm{CH}_{4}$ to $\mathrm{CO}_{2}$ /air was greater than the $\mathrm{CMC}$, the solid phase (mixed gas hydrate) and water coexisted. These products were acquired by a rapid sampling method, and water phase turns into ice phase. Therefore, the amount of the ice phase corresponds to the amount of decomposition. The recovery by replacement was determined by a GC analysis of the hydrates using same method used in the literature ${ }^{13-15}$. In this way, the total $\mathrm{CH}_{4}$ recovery and relative $\mathrm{CH}_{4}$ recovery depending on the ratio of $\mathrm{CH}_{4}$ to $\mathrm{CO}_{2}$ /air were calculated.

Spectroscopic analysis. For Raman measurements we used the Horiba Jobin Yvon LabRAM HR UV/Vis/NIR high resolution dispersive Raman microscope in which a $\mathrm{CCD}$ detector was equipped and cooled by liquid nitrogen. Samples were kept at $77 \mathrm{~K}$ during measurements. The excitation source was an Ar-ion laser emitting a

$514.53 \mathrm{~nm}$ line. The laser intensity was typically $30 \mathrm{~mW}$.

The XRD patterns were obtained using a Rigaku D/max-IIIC diffractometer with $\mathrm{CuK} \alpha$ as a light source $(\lambda=1.5406 \AA)$ at a generator voltage of $40 \mathrm{kV}$ and a generator current of $300 \mathrm{~mA}$. A low-temperature stage attached to the XRD unit maintained the working temperature at $93 \mathrm{~K}$, and a step-scan mode was applied $\left(0.02^{\circ}\right.$ step-size and 3 s per step).

The HRPD patterns were collected using PAL (Pohang Accelerator Laboratory, Republic of Korea) Synchrotron. During the measurements, the $\theta / 2 \theta$ scan mode with a fixed time of $3 \mathrm{~s}$ and a step size of $0.005^{\circ}$ for $2 \theta=0 \sim 120^{\circ}$ and the beam line with a wavelength of $1.5472 \AA$ were used for each sample. The loading of the samples was performed at $77 \mathrm{~K}$ to minimize possible sample damage.

The concentration of gaseous guest-molecules in the hydrate sample was measured using a Young-Lin 6000 (Young-Lin, Republic of Korea) gas chromatography. The samples were moved to a precooled reactor $(\sim 77 \mathrm{~K})$ each time, and it was evacuated using a vacuum pump. The gas phase was analyzed after being held at room temperature until the hydrate samples completely dissociated. Helium was used as the carrier gas, and the GC column was maintained at $55 \mathrm{kPa}$ and $353 \mathrm{~K}$.

1. Makogon, Y. F., Holditch, S. A. \& Makogon, T. Y. Natural gas-hydrates - A potential energy source for the $21^{\text {st }}$ Century. J. Pet. Sci. Eng. 56, 14-31 (2007)

2. Sloan, E. D. Fundamental principles and applications of natural gas hydrates. Nature 426, 353-359 (2003). 
3. Schoderbek, D. \& Boswell, R. Ig̈nIk SIkumI \#1, Gas Hydrate test Well, Successfully Installed on the alaska north Slope. Methane hydrate newsletter. US DOE, Fire in the ice 11, 1-5 (2011).

4. Tsuji, Y., Ishida, H., Nakamizu, M., Matsumoto, R. \& Shimizu, S. Overview of the MITI Nankai Trough wells: a milestone in the evaluation of methane hydrate resources. Resour. Geol. 54, 3-10 (2004).

5. Japan Oil, Gas and Metals National Corporation (JOGMEC). Gas production from methane hydrate layers confirmed. <www.jogmec.go.jp/english/news/ release/release0110.html>, (2013) (Date of access: 24/04/2014).

6. Bahk, J.-J. et al. Occurrence of near-seafloor gas hydrates and associated cold vents in the Ulleung Basin, East Sea. Geosci. J. 13, 347-385 (2009).

7. Lee, J. Y. et al. Physical properties of sediments from the Ulleung Basin, East Sea: results from second Ulleung Basin gas hydrate drilling expedition, East Sea (Korea). Mar. Petrol. Geol. 47, 43-55 (2013).

8. Bahk, J.-J. et al. Characterization of gas hydrate reservoirs by integration of core and log data in the Ulleung Basin, East Sea. Mar. Petrol. Geol. 47, 30-42 (2013).

9. Demirbas, A. Methane hydrates as potential energy resource: part 2 - methane production processes from gas hydrates. Energy Convers. and Manage. 51, $1562-1571$ (2010).

10. Kvenvolden, K. A. Potential effects of gas hydrate on human welfare. Proc. Natl. Acad. Sci. USA 96, 3420-3426 (1999).

11. Ohgaki, K., Takano, K., Sangawa, H., Matsubara, T. \& Nakano, S. Methane exploitation by carbon dioxide from gas hydrates-phase equilibria for $\mathrm{CO}_{2}-\mathrm{CH}_{4}$ mixed hydrate system. J. Chem. Eng. Japan 29, 478-483 (1996).

12. Lee, H., Seo, Y., Seo, Y.-T., Moudrakovski, T. L. \& Ripmeester, J. A. Recovering methane from solid methane hydrate with carbon dioxide. Angew. Chem. Int. Ed. 42, 5048-5051 (2003).

13. Park, Y. et al. Sequestering carbon dioxide into complex structures of naturally occurring gas hydrates. Proc. Natl. Acad. Sci. USA 103, 12690-12694 (2006).

14. Shin, K. et al. Swapping phenomena occurring in deep-sea gas hydrates. Energy \& Fuels 22, 3160-3163 (2008)

15. Koh, D.-Y. et al. Recovery of methane from gas hydrates intercalated within natural sediments using $\mathrm{CO}_{2}$ and a $\mathrm{CO}_{2} / \mathrm{N}_{2}$ gas mixture. ChemSusChem $\mathbf{5}$, 1443-1448 (2012).

16. Haneda, H., Sakamoto, Y., Kawamura, T. \& Komai, T. Experimental study on dissociation behavior of methane hydrate by air. Proceedings of the 5 th International Conference on Gas Hydrates. Trondheim, Norway: ICGH (2005, June 13-16).

17. Masuda, Y. et al. Prediction of methane hydrate dissociation behavior by nitrogen injection. Proceedings of the 6th International Conference on Gas Hydrates. Vancouver, Canada: ICGH (2008, July 6-20).
18. Panter, J. L., Ballard, A. L., Sum, A. K., Sloan, E. D. \& Koh, C. A. Hydrate Plug Dissociation via Nitrogen Purge: Experiments and Modeling. Energy \& Fuels 25, 2572-2578 (2011).

19. Sloan, E. D. \& Koh, C. A. Clathrate Hydrates of Natural Gases (CRC press, 2008).

20. Sum, A. K., Burruss, R. C. \& Sloan, E. D. Measurement of clathrate hydrates via Raman spectroscopy. J. Phys. Chem. B 101, 7371-7377 (1997).

21. Mohammadi, A. H., Tohidi, B. \& Burgass, R. W. Equilibrium data and thermodynamic modeling of nitrogen, oxygen, and air clathrate hydrates. J. Chem. Eng. Data 48, 612-616 (2003).

22. Lee, S., Lee, Y., Lee, J., Lee, H. \& Seo, Y. Experimental verification of methanecarbon dioxide replacement in natural gas hydrates using a differential scanning calorimeter. Environ. Sci. Technol. 47, 13184-13190 (2013).

23. Davie, M. K. \& Buffett, B. A. A numerical model for the formation of gas hydrate below the seafloor. J. Geophys. Res. 106, 497-514 (2001)

\section{Acknowledgments}

This research was supported by a grant from the National Research Foundation Korea funded by the Korean government (No. 2010-0029176).

\section{Author contributions}

K.H., K.D.-Y. and L.H. designed the research; K.H. and K.D.-Y. performed the research; K.D.-Y. and K.H. analyzed the data and K.H., K.D.-Y. and L.H. wrote the paper.

\section{Additional information}

Supplementary information accompanies this paper at http://www.nature.com/ scientificreports

Competing financial interests: The authors declare no competing financial interests. How to cite this article: Kang, H., Koh, D.-Y. \& Lee, H. Nondestructive natural gas hydrate recovery driven by air and carbon dioxide. Sci. Rep. 4, 6616; DOI:10.1038/srep06616 (2014).

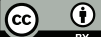

This work is licensed under a Creative Commons Attribution 4.0 International License. The images or other third party material in this article are included in the article's Creative Commons license, unless indicated otherwise in the credit line; if the material is not included under the Creative Commons license, users will need to obtain permission from the license holder in order to reproduce the material. To view a copy of this license, visit http://creativecommons.org/licenses/by/4.0/ 